\title{
Contagion of aggression and the number of reinforcements given by a model to an instigator'
}

\author{
ROBERT I. LIDMAN, ${ }^{2}$ University of \\ Iowa, Iowa City, Iowa 52240
}

The present study was concerned with effects on an $O$ of varying amounts of reinforcement given by an aggressive or rewarding model to an instigating or noninstigating confederate. There were no significant main effects of $O$ s' responses to $^{\prime}$ one hostile response by a model as opposed to four hostile responses by a model when a confederate gave an instigating opinion.

In recent years much work has been accomplished in the area of imitational learning. Bandura (1965) states “... eliciting of a previously learned deviant response through exposure to a deviant model usually, if not always, reflects a disinhibitory process." The degree and duration of the disinhibition of aggressive responses, further treated in Wheeler's (1966) theory of behavioral contagion, provides the framework of the present study. As Wheeler states, "In a situation involving several potential actions directed toward the same end or expressing the same need pattern, observation of the model's performance of Behavior A will reduce the observer's fear of performing $A^{\prime}$ as well as $A$. Depending on the relative approach gradients for $A$ and $A^{\prime}$, then, the observer may perform $A^{\prime}$ as a consequence of witnessing the performance of A." If results are in accord with this theory, no differences should exist between the amount of O's aggression expressed against an instigator aggressed against by a model after only the first opinion of four opinions, and the amount expressed by an 0 when the instigator is aggressed against by a model after each of four opinions.

In contrast to what might be expected on the basis of Wheeler's formulations, another possibility exists: permitting a model to aggress will result in vicariously reinforcing the expression of aggressive responses by an 0 . Permissiveness of an aggressive response by a model has been shown (Bandura, 1963) to have similar effects on an $\mathrm{O}$ as a rewarded aggressive response by a model. If results are in accord with this data, it is expected that an $O$ will aggress more when he sees four aggressive responses by a model than when he sees one aggressive response by a model. METHOD

The Ss, 48 paid male volunteers, were randomly and equally assigned to one of the eight independent conditions of the experiment described below.
After the S, henceforth known as "A," was placed in a soundproof room, he was told that he could communicate with, but not see, two other Ss via his response panel and his intercom. The S was told that Ss " $B$ " and " $C$ " (actually tape recorded voices of two confederates) were in similar adjoining rooms. The purpose of the study was described as an interest in how well individuals express their own opinions on certain topics and how freely they can evaluate other's opinions on the same topics. S B's "role" was to give opinions on tour general topics: parents, sex, marital roles, and war (Wheeler \& Gaggiula, 1966), always expressed in that order. S A's and S C's roles were described as essentially the same: to evaluate B's opinion in terms of "how much you feel B's opinion would contribute to group agreement." $S$ A was told his response would be of two types: a nonverbal reinforcement and a verbal reinforcement. Nonverbal reinforcement could be effected by pressing any one of 10 buttons, labeled in a $+5,+4,+3,+2,+1,-1,-2,-3,-4$, and -5 order (reversed for half the Ss). The five plus buttons ostensibly varied from "substantial money" $(+5)$ to "small amount of money" $(+1)$. The five minus buttons represented degrees of shock, -5 being "painful shock" and -1 being "mildly unpleasant shock." The Os' verbal reinforcement, given into an intercom, was of interest only to determine possible irregularities of responding. The $S$ was then told that either he or $C$ might be asked to respond first to B's opinion. If $C$ responded before $A$, the $S$ could hear C's verbal response through the intercom and see C's nonverbal reinforcement indicated on an ordinal scale of labeled jeweled lamps.

The following conditions constituted a 2 by 2 by 2 factorial design. S B gave either instigating or noninstigating opinions; $C$ either aggressed against or rewarded B. In the four instigating opinions, $B$ gave socially undesirable opinions. Noninstigating or "neutral" opinions were given on the same general topics for half the Ss. When C aggressed, Ss were shown that B had been shocked; then they heard $C$ verbally chastise $B$. When $C$ rewarded $B, S$ s were shown that $B$ had been given money; then they heard $C$ state an ambiguous response, neither complimenting nor scolding. For half the Ss, $C$ responded before $S$ after all opinions (CA). For the other half, $\mathrm{C}$ responded before $S$ only after the first opinion (AC) and $S$ could not hear or see C's response for the remaining three responses. Nonverbal rein- forcement by the model (C) was always either +3 or -3 for the first opinion, depending on whether $\mathrm{C}$ rewarded or punished B. For subsequent opinions in the CA condition, C's reinforcement was randomly and exhaustively varied between $/ 3 /$ and $/ 1 /$.

\section{The dependent measure was mean} numerical value, over five trials, of the button pressed by $S$ in response to $S B$. On these scores an extended Type III analysis of variance was performed (Lindquist, 1953). The mean reinforcement scores for eight groups for the first four opinions are graphically represented in Fig. 1. An extended Type III analysis of variance of the mean reinforcement scores on the first four opinions revealed significant main effects of instigation vs noninstigation $[F(1,40)=39.1720, p<.001]$ and model reward vs model punish $[F(1,40)=5.5760$, $p<.05]$. The main effect of instigation vs noninstigation indicated that $S$ s aggressed more in response to an instigating opinion than to a noninstigating opinion. The main effect of model reinforcement indicated that $S$ s aggressed more when a model aggressed against $B$ than when a model rewarded $B$.

The analysis of variance further indicated that differences between number of reinforcements given by a model (AC vs CA) were nonsignificant $[F(1,40)=1.1610$, $p>.10]$. This suggested that model cues for one opinion were as effective as the combined effect of cues for four opinions.

\section{DISCUSSION}

The results provide positive evidence for the formulations of contagion theory. When instigation was effectively produced, model reinforcement seemed an effective cue to subsequent reinforcement by $S$. Variation of the number of times a model reinforced $S B$ did not alter the Ss' reinforcement of S B within identical instigations. This result would indicate that restraints in the form of internal social inhibitions against aggression were lowered as effectively by one aggressive response by a model as by four aggressive responses by a model. Results were not consistent with expectations that permitting aggressive responses by a model would reinforce similar behavior in an $\mathrm{O}$ and elicit more aggressive responses by an $\mathrm{O}$ when he heard four aggressive responses by a model than when he heard one aggressive response by a model.

Of further interest in the present study were the significant differences achieved between $\mathrm{C}$-aggress and $\mathrm{C}$-reward groups as a whole. This indicated that effects of model aggression were evident even when $B$ was a noninstigator. If viewed condition by condition, these results still remained 
consistent with the framework set by contagion theory. When B was a noninstigator, his opinions would have served to evoke a rewarding response by the $O$ in the absence of an aggressive model. Aggression by a model to a noninstigated opinion caused Ss to reward the opinion-giver less than would be expected in a no-model condition. It was evident that Ss' reinforcement of the opinion-giver was approximately half-way between the aggressive model's mean reinforcement $(-2)$ and the probable reinforcement given by the naive $S$. In terms of approach-avoidance gradients conceived by Wheeler's theory of contagion (1966), these results became reconcilable within the definition of conformity. Because the avowed purpose of the study was to reach group accord, it seemed reasonable to assume a tendency toward group cohesion on the part of the Ss. Consistent with Wheeler's definition of conformity, aggression by a model to a noninstigating opinion served to introduce conflict after the model's response rather than having the model reconcile a conflict as in the contagion situation. The resultant reinforcement by the Ss was a reinforcement half-way between that expected of a naive $S$ and the aggressive model.

In the condition $C$ reward and $B$ noninstigate, it seemed unlikely that any conflict resulted and the mean reinforcement score would have changed little in the absence of the model.

In the condition $B$ instigate and $C$ reward, the resultant response by $S$ would seem to be some combination of inhibitions to aggression, upheld by a rewarding model, and the height of the approach gradient to aggression. Further research is necessary to determine the extent of model influence.

\section{REFERENCES}

BANDURA, A. Vicarious processes: A case of no trial learning. In L. Berkowitz (Ed.), Advances in experimental social psychology. Vol. 2. New York and London: Academic Press, 1965.

BANDURA, A., \& WALTERS, R. H. Social learning and personality development. New York: Holt, 1963.

LINDQUIST, E. F. Design and analysis of experiments in psychology and education. Boston: Houghton Mifflin, 1953.

WHEELER, L. Toward a theory of behavioral contagion. Psychological Review, 1966, 73, 179-191.

WHEELER, L., \& CAGGIULA, A. R. The contagion of aggression. Journal of Experimental Social Psy chology, 1966, 2, 1-10.

\section{NOTES}

1. This research was supported by the Undergraduate Research Participation Program of the National Science Foundation, Grant GY-2712. The author is indebted to Sidney J. Arenson, Charles $I$. Schmidt, and Inwin P. Levin for their aid in completing the present study.

2. Author is now at the University of Wisconsin.

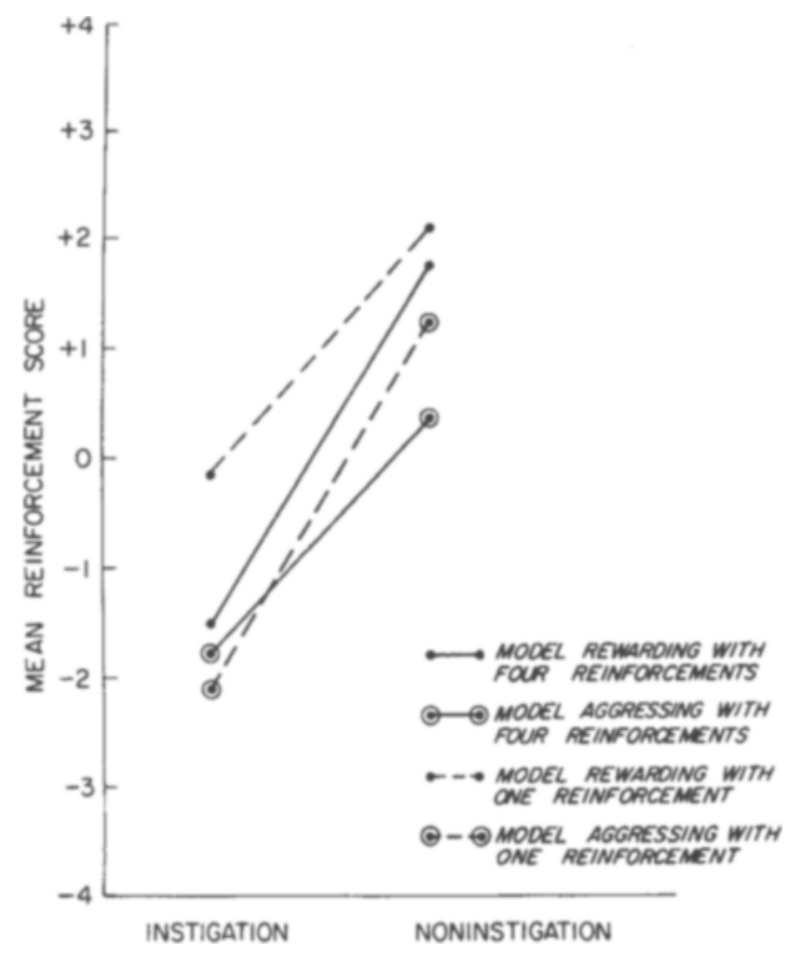

Fig. 1. Mean reinforcement scores for model aggressing or model rewarding with one or four reinforcements.

\section{Reward schedule, response measure, and attentional deficiency: A reanalysis'}

\author{
PETER WATSON, Trent University, Peter- \\ borough, Ontario, Canada
}

Part of the data of a previously published experiment were reanalyzed in order to determine whether an attentional deficiency, defined in terms of mental age (MA), would influence the superiority of partial reward relative to continuous reward. It was hypothesized that low-MA retardates, if they are deficient in an attentional process as postulated by some theorists, would not demonstrate a difference between $50 \%$ and $100 \%$ reward schedules in performance of a starting speed response, which presumably involves a large attentional component. Differences in favor of $50 \%$ reward were predicted for the low-MA Ss on a movement speed response, which does not involve attention, and for the high-MA Ss on both starting and movement speeds. Results of the reanalysis confirmed these predictions, and supported the theoretical assumptions underlying them.
Several studies with young children (see Ryan \& Watson, 1968) have shown that partial reward for a discrete-trial leverpulling response leads to faster performance than is the case for continuous reward. The superiority of partial relative to continuous reward has been attributed to the operation of frustration-produced motivation (see Amsel, 1958; Spence, 1960, Chap. 6). One difficulty with this body of evidence is that the partial-continuous difference has generally been obtained on only one of the two response measures usually employed. The author has recently in this journal presented evidence (Watson, 1968) suggesting that the type of reward employed may determine in part which response measure will show the partial-continuous difference, and indicated the need for more information concerning the various psychological processes involved in the two response measures. The present paper represents an attempt to clarify the nature of these measures, by means of a reanalysis of data presented previously in 